Elmira Bekbolatova, Wirginia Kukula-Koch*, Tomasz Baj, Natalia Stasiak, Galiya Ibadullayeva, Wojciech Koch, Kazimierz Głowniak, Saken Tulemissov, Zuriyadda Sakipova, Fabio Boylan

\title{
Phenolic composition and antioxidant potential of different organs of Kazakh Crataegus almaatensis Pojark: A comparison with the European Crataegus oxyacantha L. flowers
}

https://doi.org/10.1515/chem-2018-0048

received December 21, 2017; accepted March 1, 2018.

\begin{abstract}
The aim of this study was to investigate polyphenolic composition of different parts (leaves, flowers and fruits) of Crataegus almaatensis Pojark, an endemic plant of Kazakhstan, and compare it to a well known European Crataegus oxyacantha L. flowers. A Qual-Quant analysis was performed based on HR-MS measurements on 22 secondary metabolites: flavonoids and phenolic acids. Another goal was to evaluate the antioxidant potency of hawthorn extracts which was expressed in the total phenolic content and DPPH scavenging potency tests. Leaf extracts from $C$. almaatensis were found to be the most rich in metabolites and the most active in antiradical tests (IC ${ }_{50}$ value of $48 \mu \mathrm{g} / \mathrm{ml}$ and TPC of $218 \mathrm{mg} / \mathrm{g}$ ). The weakest potential was determined for the fruit extract of this species. According to the performed principal component
\end{abstract}

\footnotetext{
*Corresponding author: Wirginia Kukula-Koch, Department of Pharmacognosy with Medicinal Plants Unit, Medical University of Lublin, 1 Chodzki Str., 20-093 Lublin, Poland, E-mail: virginia.kukula@gmail.com Elmira Bekbolatova, Galiya Ibadullayeva, Zuriyadda Sakipova: School of Pharmacy, Asfendiyarov Kazakh National Medical University, 94 Tolebi street, 050000, Almaty, Kazakhstan Tomasz Baj, Natalia Stasiak: Department of Pharmacognosy with Medicinal Plants Unit, Medical University of Lublin, 1 Chodzki Str., 20-093 Lublin, Poland

Wojciech Koch: Department of Food and Nutrition, Medical University of Lublin, 4a Chodzki Str., 20-093 Lublin, Poland Kazimierz Gtowniak: Department of Cosmetology, University of Information, Technology and Management in Rzeszow, Kielnarowa 386a, 36-020 Tyczyn, Poland

Saken Tulemissov: Department of Chemistry and Biology, Kazakhstan Engineering and Pedagogical University of Friendship of Peoples, 32 Tole bi street, Shymkent, Kazakhstan

Fabio Boylan: School of Pharmacy and Pharmaceutical Sciences, Panoz Institute, Trinity College, Dublin 2, Ireland
}

analysis (PCA), the fruit extracts were not correlated with other organs of the plant, and the metabolites responsible for the extracts' differentiation were cyanidin 3-glucoside and quercetin 3-galactoside. Based on a high correlation factor, the flowers of the Kazakh species was found to be as rich in polyphenols as the European hawthorn. The results of this study indicate that $C$. almaatensis is a promising source of natural antioxidants.

Keywords: hawthorn; LC-MS; antioxidant tests; Kazakhstan; flavonoids.

\section{Introduction}

Hawthorn is one of the oldest widely used herbal plant popularly prescribed in central Europe and known in Asian countries, with a wide spread usage in China. It can be spread in the form of trees or shrubs, and encompasses around 280 species all over the world. This plant is distributed in temperate areas of Europe, North America, North Africa, India, China and Western Asia. Different species of hawthorn are characteristic to specific regions such as Crataegus pinnatifida Bunge (Chinese hawthorn), C. pubescens Steud. (Mexican hawthorn), C. cuneate Rehder ex C.K.Schneid (Japanese hawthorn), C. laevigata (Poir.) DC and C. monogyna Jacq. (Europe), C. oxyacantha L. and C. aronia var. aronia (L.) Bosc. Ex Dc (Middle East), C. phaenopyrum Borkh. (American hawtrorn) and C. ambigua A.K.Becker (Russian hawthorn). C. monogyna. and C. laevigata are described in the European and United states Pharmacopoeia, while as C. pinnatifida, C. pinnatifida are official species in the Chinese Pharmacopoeia [1-5]. It is always of particular interest to study the composition of endemic plants, as they may contain higher amount of chemicals. Often their phytochemical properties and 
medicinal usage are well documented by the traditional medicinal system of their own region [6].

In the case of Crataegus, a broad range of biological activities important for both folk and official medical practices has been described, including its anti-oxidant, anti-inflammatory, vasodilator, positive inotropic, and cholesterol synthesis inhibiting properties [7]. The abovementioned activities are strongly affected by the presence of antioxidant molecules in this plant's extracts, which have an ability to scavenge free radicals, produced as a result of biochemical and physiological reactions in the human body. Free radicals, if produced in excess or in a haphazard way, can affect the human body and lead to various chronic diseases, such as cardiac diseases, diabetes, or cancer. Epidemiological studies have demonstrated that natural products with free radical scavenging activity can attenuate the hazard effects of free radicals and show anti-inflammatory, antiatherosclerotic, antitumor, antimutagenic, anticarcinogenic, antibacterial, antiviral activities, among others [8]. This can explain the positive effect of hawthorn on conditions such as hypertension, arrhythmia or atherosclerosis [7]. Oligomeric procyanidins, triterpenes, flavonoids, polysaccharides, and catecholamines were identified in hawthorn extracts and are responsible for its pharmacological potential [6, 9].

Either fresh or dried fruits, flowers and leaves of Crataegus species are used for the preparation of teas or as a source of extracts for the production of various dosage forms of over-the-counter medicines or dietary supplements [10].

The Republic of Kazakhstan has several wild growing hawthorn species. One of which is spread in the Ile Alatau region (mountains) of Kazakhstan named Crataegus almaatensis Pojark. There are only a few scientific papers on the chemistry of cultivated Crataegus almaatensis fruits, which encouraged the authors to study the composition of this particular species. Scarce data suggest that Crataegus almaatensis fruits may contain carotenoids, sugars and organic acids [11,12], however there is no information on its phenolic composition.

In a continuous effort to understand the chemistry and pharmacology of endemic medicinal Kazakh plants $[13,14]$ a comparison between the phenolic composition of the European and the Kazakh hawthorn species, and the establishment of their antioxidant activity were the aims of this study.

\section{Materials and Methods}

\subsection{Plant Material}

The extracts investigated in the study were obtained from fruits, leaves and flowers of Crataegus almaatensis collected at the foothills of Ile Alatau Mountains, in Medeo valley, Almaty region, Kazakhstan in September 2015 (fruits) and May 2016 (flower and leaves) and authenticated by Institute of Botany and Phytointroduction, Almaty, Kazakhstan, by the head of the High Plant Flora Laboratory, candidate of biological sciences Dr. G. Kudabayeva and confirmed by general director doctor of biological sciences G. Sitpayeva (reference letter 01-04/456 from 10.11.2015).

Dried and ground flower of Crataegus oxyacantha produced by Herbapol Lublin was purchased from a local pharmacy in September 2016 and were introduced into the comparative study. All studied plant samples were given voucher specimen numbers (WKK1601005 - for the fruits, WKK1601006 - for the leaves, WKK1601007 - for the flowers of C.almaatensis, and WKK1601008 - for the flowers of $C$. oxyacantha) and the samples are stored in the Chair and Department of Pharmacognosy with Medicinal Plants Unit at Medical University of Lublin, Poland.

\subsection{Reagents}

Ethanol and methanol (reagent grade purity) used for the preparation of extracts, DMSO, and Folin-Ciocalteu reagents were obtained from Avantor Performance Materials (Center Valley, PA, USA). The LC-MS analysis was performed using acetonitrile, water and formic acid (spectroscopic grade), which were purchased from J. T. Baker (Center Valley, PA, USA). Ammonium formate and all reference compounds (including quercetine used as a reference in antioxidant studies) of purity $>95 \%$ were purchased from Sigma Aldrich (St. Louis, LA, USA).

\subsection{Extracts preparation}

Two gram portions of dried and powdered plant material (both Crataegus almaatensis. flower, fruit, leaves, and Crataegus oxyacantha flowers) were each suspended in 10 $\mathrm{mL}$ of either $96 \%$ ethanol or $50 \%$ ethanol. The prepared solutions were sonicated at $30^{\circ} \mathrm{C}$ for $30 \mathrm{~min}$ and then filtered through a nylon syringe filter $(0.45 \mu \mathrm{m}$ pore size diameter, Cronus) into HPLC vials and test tubes. The solutions were dried under vacuum at $30^{\circ} \mathrm{C}$ (in Eppendorf 
Concentrator Plus) until dryness, weighted and used in the LC-MS quantification experiments and antioxidant assays.

\subsection{LC-MS determination of phenolic content of the studied extracts}

Phenolic compounds were identified and quantified using HPLC-ESI-Q-TOF-MS and HRMS/MS method. The experiments were performed using an Agilent Technologies LC system (1260) (Santa Clara, CA, USA) with a binary pump (G1312C), an autosampler (G1329B), a column oven (G1316A), a degasser (G1322A) and a PDA detector (G1315D), coupled with an ESI-Q-TOF-MS detector (G6530B). The system operated both in positive and negative modes and enabled qualitative and quantitative determination of the extracts' constituents. An Agilent MassHunter software was employed for system operation and spectral data analysis.

The samples were filtered through a nylon syringe filter $(0.45 \mu \mathrm{m}$ pore size diameter, Cronus) prior to the LC-MS analyses. Chromatographic separation was carried out using an Agilent Technologies (Santa Clara, CA, USA) Zorbax Stable Bond RP-18 column (150 mm x $2.1 \mathrm{~mm}$, dp = $3.5 \mu \mathrm{m}$ ), with a temperature set up at $20^{\circ} \mathrm{C}$. The injected volume was $10 \mu \mathrm{L}$. The following gradient of solvents was employed using two solvents - A $0.1 \%$ of formic acid solution - and B 95\% acetonitrile 5\% formic acid (0.1\%): 0 $\min -1 \%$ of B in A, $70 \min -55 \%$ of B in A, $77 \min -95 \%$ of $B$ in $A, 83 \min -95 \%$ of $B$ in $A$. The run time was set at $90 \mathrm{~min}$ and the flow rate was $0.2 \mathrm{~mL} / \mathrm{min}$. The length of the method was influenced by the high quantity of metabolites present in each sample, especially those of high polarity.

The MS detector conditions were set up to optimize the fragmentor and source parameters. The gas temperature was $350^{\circ} \mathrm{C}$, sheath gas temperature $400^{\circ} \mathrm{C}$, gas and sheath gas flows: $12 \mathrm{~L} / \mathrm{min}$, nebulizer gas pressure: $35 \mathrm{psig}$, fragmentation, capillary, nozzle and skimmer voltages of: $130 \mathrm{~V}, 4000 \mathrm{~V}, 1000 \mathrm{~V}$, and $65 \mathrm{~V}$, respectively.

After optimization, the MS/MS spectra were recorded for two of the most abundant signals at a given time, which were subsequently excluded for the next 0.3 min to enable fragmentation of less intensive spectra. To determine the extracts' constituent structures, both mild and strong fragmentation results were provided by recording the product spectra using two collision energies (CID): $15 \mathrm{~V}$ and $25 \mathrm{~V}$. The characteristic mass fragments were identified and compared to the ones reported in the scientific literature (see Table S2 in the Supplementary Material).

The system was tuned and calibrated with the application of an external calibration mixture produced by Agilent Technologies (Santa Clara, CA, USA).

For the quantitative analysis of major metabolites, reference compounds (rutin for flavonoid glucosides, gallic acid for benzoic acid derivatives, caffeic acid for cinnamic acid derivatives, catechin and epicatechin gallate for catechins and anthocyanins) at the concentration of $0.1,0.075,0.005,0.0025$ and $0.001 \mathrm{mg} / \mathrm{mL}$, each, were injected in the same chromatographic conditions. For each standard compound, a calibration curve was obtained and subsequently used for the quantification of metabolites present in the prepared extracts. The peak areas of reference compounds covered the peak areas of the tested solutions.

Flavonoids, anthocyanins and catechins present in the prepared extracts were determined by positive mode of system operation, while phenolic acids and simple organic acids were identified in negative ionization mode (see Table 1).

\subsection{Determination of Antioxidant Activity}

All extracts from Crataegus almaatensis (flower, fruits, leaves) and Crataegus oxyacantha (flowers) were assayed for their ability to scavenge free radicals using a 1,1diphenyl-2-picrylhydrazyl (DPPH) assay modified by Lee and colleagues [15,16]. A solution of $0.2 \mathrm{mg} / \mathrm{mL}$ DPPH in ethanol was prepared right before the analyses, $5 \mathrm{mg}$ of each extract was dissolved in $1 \mathrm{~mL}$ of dimethyl sulfoxide (DMSO) and kept as a stock solution. The obtained $5 \mathrm{mg} /$ $\mathrm{mL}$ stock solutions were used to prepare several dilutions of extracts corresponding to: 25, 50, 100, 250, 500, 1000, 1500 and $2000 \mu \mathrm{g} / \mathrm{mL}$ of extract in DMSO. Later $0.1 \mathrm{~mL}$ of the test solution and obtained dilutions were transferred to a test tube and $1.9 \mathrm{~mL}$ of DPPH radical solution was added. The reaction mixtures were left for $30 \mathrm{~min}$ at $37^{\circ}$ in a dark place. A blank containing $1.9 \mathrm{~mL}$ of DPPH and $0.1 \mathrm{~mL}$ DMSO with no addition of extract was prepared. The absorbance of all samples was measured at $515 \mathrm{~nm}$ on a UV spectrometer (Genesys 10S VIS, Thermo Scientific, Waltham, MA, USA). The obtained absorbance values were plotted against the concentration for each sample. Antiradical DPPH activity was expressed as $\mathrm{IC}_{50}$ in $\mathrm{mg} /$ $\mathrm{mL}$ representing the sample's concentration needed to scavenge $50 \%$ of DPPH free radicals and was referred to the $\mathrm{IC}_{50}$ value of an active reference compound. 
Table 1: LC-MS determination of major constituents from Crataegus almaatensis extracts. (DBE - double bond equivalent, Rt - retention time, Delta - difference between experimental and calculated masses).

\begin{tabular}{|c|c|c|c|c|c|c|c|c|c|c|}
\hline No & $\begin{array}{l}\text { lon } \\
(+/-)\end{array}$ & Rt (min) & $\begin{array}{l}\text { Molecular } \\
\text { formula }\end{array}$ & $\begin{array}{l}m / z \\
\text { experimental }\end{array}$ & $\begin{array}{l}m / z \\
\text { calculated }\end{array}$ & $\begin{array}{l}\text { Delta } \\
\text { (ppm) }\end{array}$ & $D B E$ & $\begin{array}{l}\text { MS/MS } \\
\text { fragments }\end{array}$ & Proposed compound & References \\
\hline 1 & $(+)$ & 24.194 & $\mathrm{C}_{15} \mathrm{H}_{10} \mathrm{O}_{7}$ & 303.0508 & 303.0499 & -2.88 & 11 & $229,165,137$ & Quercetin & 18 \\
\hline 2 & $(+)$ & 21.043 & $\mathrm{C}_{7} \mathrm{H}_{6} \mathrm{O}_{4}$ & 153.054 & 153.0546 & 4.08 & 5 & 135,109 & Gentisic acid & 39,40 \\
\hline 3 & $(-)$ & 26.161 & $\mathrm{C}_{21} \mathrm{H}_{20} \mathrm{O}_{11}$ & 447.0956 & 447.0922 & -7.65 & 13 & $301,205,161$ & Quercitrin & 18 \\
\hline 4 & $(-)$ & 25.687 & $\mathrm{C}_{11} \mathrm{H}_{12} \mathrm{O}_{5}$ & 223.06 & 223.0601 & 0.45 & 7 & 163 & Sinapinic acid & 16,18 \\
\hline 5 & $(-)$ & 19.402 & $\mathrm{C}_{16} \mathrm{H}_{18} \mathrm{O}_{9}$ & 353.0895 & 353.0867 & -3.1 & 9 & 191,85 & Chlorogenic acid & $16,18,39$ \\
\hline 6 & $(+)$ & 20.471 & $\mathrm{C}_{21} \mathrm{H}_{21} \mathrm{O}_{11}$ & 449.1083 & 449.1078 & -0.36 & 12 & 195 & Cyanidin 3-glucoside & 38 \\
\hline 7 & $(+)$ & 20.117 & $\mathrm{C}_{15} \mathrm{H}_{14} \mathrm{O}_{6}$ & 291.0863 & 290.0785 & 12.07 & 9.5 & $177,159,215$ & Catechin & 37 \\
\hline 8 & $(+)$ & 20.556 & $\mathrm{C}_{15} \mathrm{H}_{14} \mathrm{O}_{7}$ & 307.0785 & 307.0812 & 8.29 & 9 & $185,289,261$ & Epigallocatechin & 37 \\
\hline 9 & $(-)$ & 21.585 & $\mathrm{C}_{27} \mathrm{H}_{29} \mathrm{O}_{16}$ & 609.1498 & 609.145 & -7.87 & 14 & $461,300,151$ & Rutin & 18 \\
\hline 10 & $(-)$ & 19.402 & $\mathrm{C}_{7} \mathrm{H}_{12} \mathrm{O} 6$ & 191.0628 & 191.055 & -14.13 & 3 & 127,85 & Quinic acid & 18,41 \\
\hline 11 & $(-)$ & 25.434 & $\mathrm{C}_{21} \mathrm{H}_{20} \mathrm{O}_{12}$ & 463.0879 & 463.0882 & 0.65 & 12 & 301,127 & $\begin{array}{l}\text { Quercetin 3-glucoside } \\
\text { (isoquercetin) }\end{array}$ & 38 \\
\hline 12 & $(-)$ & 14.902 & $\mathrm{C}_{7} \mathrm{H}_{6} \mathrm{O}_{4}$ & 153.0261 & 153.0193 & -0.44 & 5 & $\mathrm{x}$ & Protocatechuic acid & 16,18 \\
\hline 13 & $(-)$ & 3.226 & $\mathrm{C}_{9} \mathrm{H}_{8} \mathrm{O}_{3}$ & 163.0468 & 163.0401 & -2.64 & 6 & $\mathrm{x}$ & p-coumaric acid & 16,39 \\
\hline 14 & $(-)$ & 19.57 & $\mathrm{C}_{9} \mathrm{H}_{8} \mathrm{O}_{3}$ & 163.0468 & 163.0401 & -2.64 & 6 & $x$ & m-Coumaric acid & 16 \\
\hline 15 & $(-)$ & 21.134 & $\mathrm{C}_{9} \mathrm{H}_{8} \mathrm{O}_{3}$ & 163.0468 & 163.0401 & -2.64 & 6 & $\mathrm{x}$ & o-Coumaric acid & 16,39 \\
\hline 16 & $(-)$ & 22.275 & $\mathrm{C}_{27} \mathrm{H}_{30} \mathrm{O}_{14}$ & 578.5176 & 577.1563 & -2.28 & 13 & $\begin{array}{l}451,425,413 \\
407,289\end{array}$ & $\begin{array}{l}\text { Vitexin 2"-0- } \\
\text { rhamnoside }\end{array}$ & 42 \\
\hline 17 & $(-)$ & 24.177 & $\mathrm{C}_{27} \mathrm{H}_{30} \mathrm{O}_{14}$ & 578.519 & 577.1563 & -5.22 & 13 & $413,293,173$ & $\begin{array}{l}\text { Vitexin 4"-0- } \\
\text { rhamnoside }\end{array}$ & 42 \\
\hline 18 & $(-)$ & 22.628 & $\mathrm{C}_{21} \mathrm{H}_{20} \mathrm{O}_{10}$ & 432.378 & 431.0984 & -7.47 & 12 & 311,413 & Vitexin & 39 \\
\hline 19 & $(-)$ & 24.751 & $\mathrm{C}_{27} \mathrm{H}_{30} \mathrm{O}_{15}$ & 593.1522 & 593.1512 & -1.69 & 13 & $\mathrm{x}$ & Vitexin 4"-0-glucoside & 42 \\
\hline 20 & $(-)$ & 24.926 & $\mathrm{C}_{23} \mathrm{H}_{22} \mathrm{O}_{13}$ & 505.0986 & 505.0988 & 0.32 & 13 & 423,300 & Quercetin glucoside & 39 \\
\hline 21 & $(-)$ & 20.421 & $\mathrm{C}_{15} \mathrm{H}_{18} \mathrm{O}_{9}$ & 341.0873 & 341.0878 & 1.48 & 7 & $251,179,161$ & $\begin{array}{l}\text { Caffeic acid } \\
\text { 3-glucoside }\end{array}$ & 42 \\
\hline 22 & $(-)$ & 19.496 & $\mathrm{C}_{9} \mathrm{H}_{8} \mathrm{O}_{4}$ & 179.0338 & 179.035 & 6.57 & 6 & 135 & Caffeic acid & 16,18 \\
\hline
\end{tabular}

\subsection{Determination of Total Polyphenolic Content}

Quantification of polyphenols in the obtained extracts was performed according to the previously published protocols $[15,17,18]$ using the Folin-Ciocalteu assay with modifications. Since the antioxidant activity of the samples was confirmed by DPPH test, the total polyphenolic content was subsequently calculated.

Different concentrations of gallic acid solutions in (DMSO) were prepared: 25, 75, 100, $200 \mu \mathrm{g} / \mathrm{mL}$. Half mililitre of each prepared solution was mixed with $2.5 \mathrm{~mL}$ of diluted Folin-Ciocalteu reagent $(0.25 \mathrm{~mL}$ of the reagent with $2.25 \mathrm{~mL}$ of distilled water) and $2 \mathrm{~mL}$ of $7.5 \%$ sodium carbonate and left for $30 \mathrm{~min}$ in a dark container. After that time, the absorbance was measured at $765 \mathrm{~nm}$ on a UV spectrometer (Genesys 10S VIS, Thermo Scientific, Waltham, MA, USA). A blind probe (sample without gallic acid) was used as reference solution.

Next, the $2 \mathrm{mg} / \mathrm{mL}$ solution of gallic acid in DMSO was used as a stock solution for the preparation of calibration curve $(25,75,100,200,250,300,350,400$, 800 and $1000 \mu \mathrm{g} / \mathrm{mL}$ ), while all obtained extracts of hawthorns were stored at a concentration of $5 \mathrm{mg} / \mathrm{mL}$ and were further diluted to 500 and $1000 \mu \mathrm{g} / \mathrm{mL}$ prior to the test. The total polyphenolic content was calculated and expressed as gallic acid equivalents (GAE) according to the calibration curve for this phenolic acid, previously prepared, which provided the following equation $\mathrm{y}=$ $1.3108 \ln (\mathrm{x})-4.1964$. 


\subsection{Statistical evaluation}

Statistical analysis of data was made using the MSExcel 2013 and Statistica 12 program (StatSoft Inc., USA). The correlation between alcoholic and alcohol-water extracts (50\%) from flowers, leaves and fruits of $C$. almaatensis and $C$. oxyacantha flower extracts was assessed. Also, the principal component analysis (PCA) was conducted. All analytical measurements were repeated six times for each sample and reference compounds. The obtained results were expressed as the mean values \pm standard deviation (SD). The significance of the obtained results was determined at $\mathrm{P}<0.05$ performing $\mathrm{t}$-test for the applied methods.

Ethical approval: The conducted research is not related to either human or animals use.

\section{Results and Discussion}

\subsection{Qualitative and quantitative LC-MS analysis of the extracts}

Polyphenolic compounds constitute a widespread group of secondary metabolites. As previously described many biological effects of various plant species depend on their secondary metabolites. In the case of Crataegus species, the phenolic ones play a very important role. This is why it is crucial to determine the phenolic content in different organs of Crataegus almaatensis and compare it to the European species Crataegus oxyacantha [8].

The applied LC-MS method enabled the qualitative and quantitative analysis of the studied samples. According to the scientific literature, flavonoids and proanthocyanidins are the main constituents of Crataegus species [19]. In our study 22 compounds (12 flavonoids and 10 phenolic acids) were identified in either $96 \%$ or $50 \%$ ethanol extracts of Crataegus almaatensis flower, fruit and leaves and in Crataegus oxyacantha flowers (Table 1). The identification was performed based on the scientific literature, spectra of some reference compounds, accurate mass measurements and MS/MS spectra of the determined compounds. The application of HRMS-MS analysis succeeded in high accuracy mass measurements, with an error of less than $15 \mathrm{ppm}$. Clear MS/MS spectra were recorded for the major compounds present in the extracts at the given collision energies (see Supplementary Material).

The quantitative analysis was based on the calibration curves equations obtained for reference compounds: rutin, gallic acid, caffeic acid, catechin and epicatechin gallate at the following concentrations: 0.1, 0.075, 0.005, 0.0025 and $0.001 \mathrm{mg} / \mathrm{mL}$. The values of R-squared for all calculated calibration curves were higher than 0.997 and the equations were as listed below: $y=8073128 x+210308$ for rutin, $y=38044768 x+119640$ for gallic acid, $y=17244017 x-$ 683396 for caffeic acid, $y=4120762 x-89363$ for catechin and $y=524315083 x+247706$ for epicatechin gallate.

The comparative results of the quantitative studies are collected in the table 2 .

Ethanol at $50 \%$ was found to be a better solvent to extract hawthorn's metabolites. Among the selected compounds for the studies, only two - vitexin and gentisic acid were present in similar quantities in both extracts. Because of this fact, the quantitative analysis of extracts is only discussed for 50\% ethanol extracts.

The most predominant components of the studied extracts were mono- and di- glycosylated derivatives of flavonols and flavones. The major flavonol present in all parts of Crataegus almaatensis was hyperoside, which is in accordance with former studies on other Crataegus species [20]. According to the literature, hyperoside is known to be the main component of Crataegus flowers [21]. Its quantity in C. almaatensis flowers calculated as $3.34 \mathrm{mg} / \mathrm{g}$ DW was almost two times higher than in the European species $(1.58 \mathrm{mg} / \mathrm{g} \mathrm{DW})$ [22], flowers of Crataegus microphylla C. Koch $(0.25 \mathrm{mg} / \mathrm{g})$ [23] and was not detected in Crataegus pinnatifida by Liu et al [24]. Leaves of Crataegus almaatensis contained $2.19 \mathrm{mg} / \mathrm{g}$ DW of this metabolite, which is comparable with $2.51 \mathrm{mg} / \mathrm{g}$ fresh weight in Crataegus azarolus L. species, but higher than Crataegus monogyna $1.45 \mathrm{mg} / \mathrm{g}$ fresh weight [25] and Crataegus microphylla $0.38 \mathrm{mg} / \mathrm{g}$ content [23]. Hyperoside content in Crataegus pinnatifida collected in May at the same time as Crataegus almaatensis is much lower being $0.01 \mathrm{mg} / \mathrm{g}$ DW [26] and this compound was not present in Crataegus pinnatifida [24,27].

Regarding the content of flavonol glycosides, fruits were found to contain smaller quantities of these compounds in comparison to other parts of the plant. The amount of hyperoside found in the fruits of Crataegus almaatensis $(0.70 \mathrm{mg} / \mathrm{g}$ DW) corresponded to the one obtained for the Crataegus aronia var aronia $0.61 \mathrm{mg} / \mathrm{g}$ fruit extract [28], but was higher than those from the three Chinese hawthorn varieties (0.25-0.50 mg/g DW) [29-31].

The second major compound - rutin, was also present in all parts of the plant material. The content of rutin ( 0.66 $\mathrm{mg} / \mathrm{g} \mathrm{DW}$ ) in the flowers of Crataegus almaatensis was slightly higher than the one found in Crataegus oxyacantha samples $(0.53 \mathrm{mg} / \mathrm{g} \mathrm{DW})$ and stays within the average value of rutin content $(0.097-1.186 \mathrm{mg} / \mathrm{g})$ determined for Crataegus azarolus var aronia. On the other hand, Crataegus azorolus 


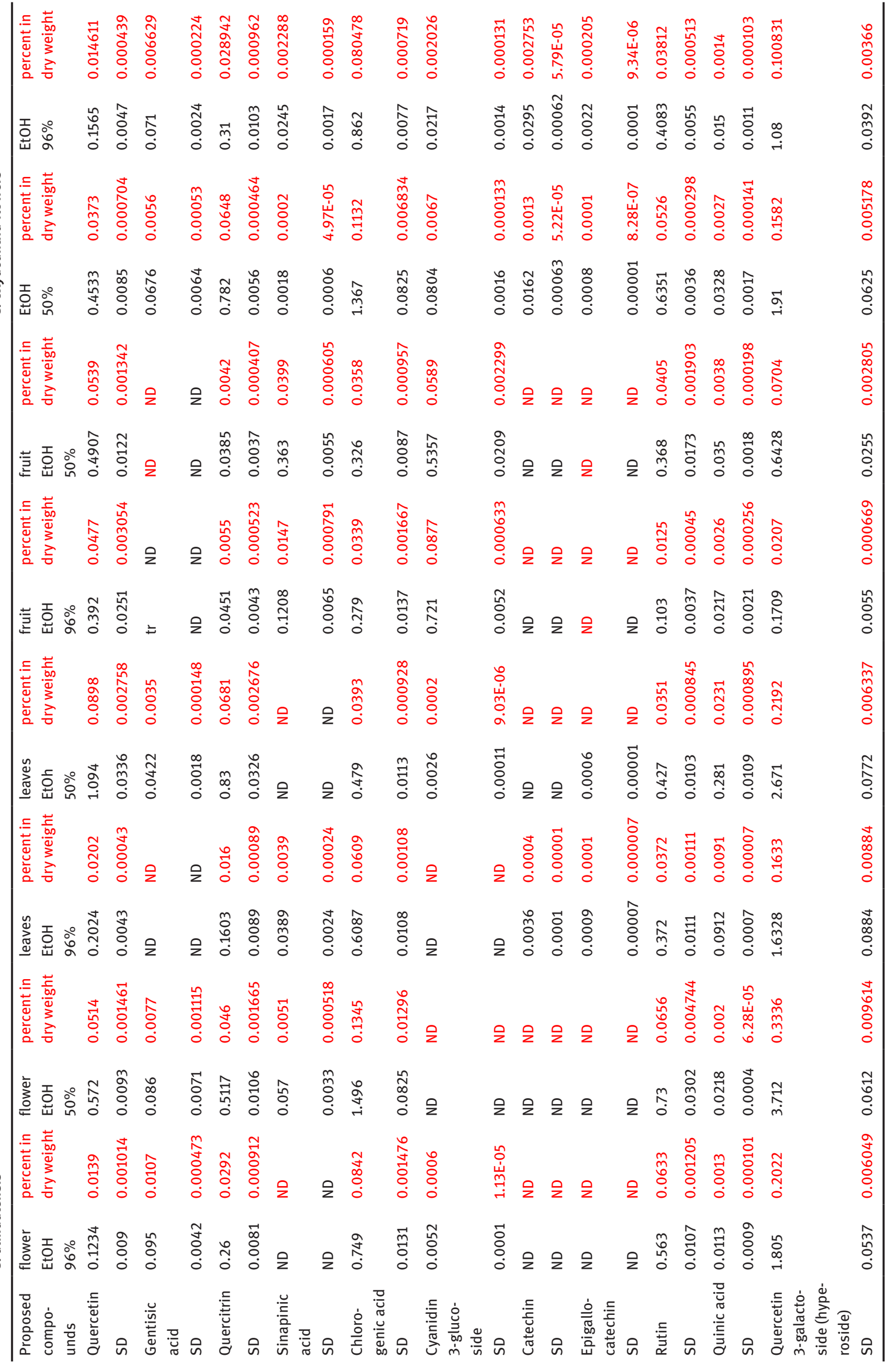




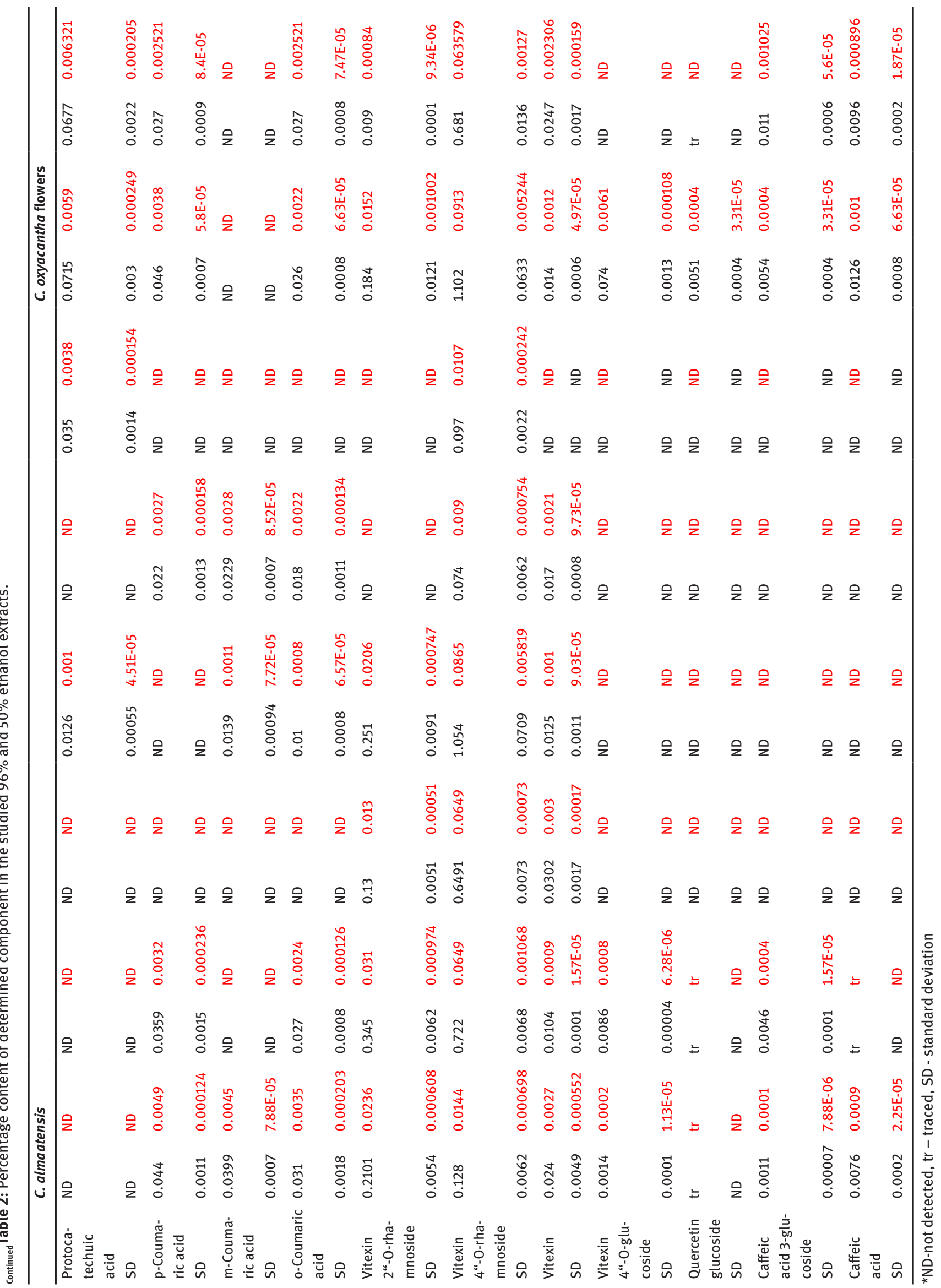


var azarolus (0.161-0.615mg/g DW) contained smaller quantities of this flavonoid diglycoside [22]. Rutin in the leaves of the Kazakh species was calculated as $0.35 \mathrm{mg} / \mathrm{g}$ DW and this quantity is comparable with that previously published for the Crataegus monogyna $0.329 \mathrm{mg} / \mathrm{g}$ in fresh leaves [25], but significantly higher than those found for C. pinnatifida leaves $(0.09 \mathrm{mg} / \mathrm{g}$ in the samples) $[24,27]$. In the fruits of Crataegus almaatensis rutin was present at the concentration $0.40 \mathrm{mg} / \mathrm{g} \mathrm{DW}$, a bit higher than the Crataegus azarolus and Crataegus monogyna sum of the peel and pulp rutin content $(0.29$ and $0.18 \mathrm{mg} / \mathrm{g}$ fresh weight respectively) [25], however, Chinese hawthorn fruits were proven to contain very low concentration of this flavonoid - namely, $0.007 \mathrm{mg} / \mathrm{g}$ in the samples and $0.026 \mathrm{mg} / \mathrm{g}$ DW $[24,27,29]$.

Rhamnoside glucosides of quercitrin and vitexin (4"'$O$-rhamnoside) were abundantly present in the flowers. It is worth mentioning that Crataegus almaatensis flowers and fruits contained less quercitrin $(0.46 \mathrm{mg} / \mathrm{g}$ and 0.042 $\mathrm{mg} / \mathrm{g}$ DW, respectively) than Crataegus oxyacantha (0.65 $\mathrm{mg} / \mathrm{g}$ DW), but its leaves contain similar quantity (0.68 $\mathrm{mg} / \mathrm{g}$ ) of this metabolite when compared to the reference extract of hawthorn. The same pattern was recorded for vitexin 4"-O-rhamnoside. According to Melikoglu and co-workers, Crataegus microphylla leaf extracts contained $0.01 \mathrm{mg} / \mathrm{g}$ of vitexin 4"-O-rhamnoside, which was not present in its flowers [23]. This amount is far lower than the one obtained in this study. Vitexin 4"-O-rhamnoside was calculated to be one of the major components of the Crataegus almaatensis extract and its quantity accounts for $0.87 \mathrm{mg} / \mathrm{g}$ DW in the leaf extracts and $0.65 \mathrm{mg} / \mathrm{g}$ DW in the flowers). There is not much research work on the quantification of quercitrin and vitexin 4"-O-rhamnoside in other Crataegus species. Also, Vitexin 2"-O-rhamnoside was found to be abundantly present in the Kazakh hawthorn leaves and flowers in comparison to its quantity in Crataegus oxyacantha. According to our study, fruits did not contain this glycoside, which stays in accordance with scientific literature. Orhan and co-workers state that this flavonoid glycoside was not present in the fruits of Crataegus aronia var. aronia, C. monogyna or $C$. pseudoheterophylla Pojark. [28]. However, its presence was identified in C. pinnatifida fruits [24,27].

Also, Crataegus almaatensis flowers are a richer source of the flavonol quercetin $(0.51 \mathrm{mg} / \mathrm{g} \mathrm{DW})$ in comparison to C. oxyacantha $(0.37 \mathrm{mg} / \mathrm{g} \mathrm{DW}), C$. azarolus var. aronia (0.032-0.248 mg/g DW), C. azorolus var. azarolus (0.02$0.18 \mathrm{mg} / \mathrm{g} \mathrm{DW}$ ) [22], and C. microphylla (0.06 mg/g) [23]. Quercetin in the leaves of Crataegus almaatensis (0.90 $\mathrm{mg} / \mathrm{g} \mathrm{DW}$ ) is also higher than in the leaves of hawthorn species collected in west Azerbaijan and Iran $(0.12 \mathrm{mg} / \mathrm{g}$ in the dried extracts) [32] and C. laevigata $(0.24 \mathrm{mg} / \mathrm{g}$ methanol extracts) determined by Mojka and co-authors [33]. Its presence is reduced in fruits $(0.54 \mathrm{mg} / \mathrm{g} \mathrm{DW})$. The latter concentration is high in comparison with Crataegus monogyna fruits $(0.046 \mathrm{mg} / \mathrm{g})$ [32] and the fruits of Chinese species $(0.009 \mathrm{mg} / \mathrm{g}$ DW) [29].

Among simple phenolics, hydrocinnamic acid derivatives were mostly present in the studied samples. Chlorogenic acid, the most important one, has been found in all investigated hawthorn species so far [20]. Its quantity in Crataegus almaatensis and C. oxyacantha flowers were on a similar level, ranging around 1.13-1.35 $\mathrm{mg} / \mathrm{g}$ DW. This amount is much higher than the results obtained for Crataegus azarolus var aronia (0.178-0.890 $\mathrm{mg} / \mathrm{g} \mathrm{DW})$, and C. azorolus var azarolus $(0.166-0.296 \mathrm{mg} / \mathrm{g}$ DW) [22]. However, Belkhir and co-workers determined its presence in the leaves of Crataegus azorolous to be 0.87 $\mathrm{mg} / \mathrm{g}$ fresh weight, which was higher than what is here described for $C$. almaatensis content $(0.39 \mathrm{mg} / \mathrm{g} \mathrm{DW})$ and also higher than in $C$. monogyna ( $0.17 \mathrm{mg} / \mathrm{g}$ fresh weight) [25]. This phenolic acid was also found in the fruits (0.36 $\mathrm{mg} / \mathrm{g} \mathrm{DW}$ ), at a lower concentration from previously reported Chinese samples [30]. Interestingly, the fruits themselves contained antocyanin - cyanidin -3-glucoside at $0.59 \mathrm{mg} / \mathrm{g} \mathrm{DW}$, compound that was not found in other parts of the plant.

The performed quantitative studies of the extracts composition showed that Crataegus almaatensis is a rich source of polyphenols - both phenolic acids and flavonoids and contains larger quantities of the majority of the studied compounds in comparison to the previously characterized hawthorn species. Both flowers and leaves contained a multitude of components at a higher concentration, which is shown in the Figure S1 of the Supplementary Material. Also, the similarities between the obtained extracts are presented in the dendrogram figure S3 of the Supplementary File. Based on the obtained results it can be concluded, that the content of active compounds in the fruits of the Kazakh hawthorn was average, as other species were found to contain higher quantities of polyphenols in their fruit extracts.

\subsection{Statistical analysis}

Thedifferencein the composition of thefruits in comparison to the other studied extracts was well visualized in the statistical tests. Within Crataegus almaatensis there is a very high correlation between the components of ethanol extracts from flowers and leaves, namely: 0.8528 to 0.9819 (Table 3) regardless of the solvent used. Also, a high 
Table 3: The correlation values obtained for all tested extracts.

\begin{tabular}{|c|c|c|c|c|c|c|}
\hline \multirow[t]{2}{*}{ Variable } & \multicolumn{6}{|c|}{ C. almaatensis } \\
\hline & FL_96\% & FL_50\% & LE_96\% & LE_50\% & FR_96\% & FR_50\% \\
\hline FL_96\% & 1.0000 & $0.9819^{*}$ & $0.9418^{\star}$ & $0.8528^{\star}$ & 0.1853 & $0.6320^{*}$ \\
\hline FL_50\% & $0.9819^{\star}$ & 1.0000 & $0.9783^{*}$ & $0.9168^{*}$ & 0.2212 & 0.6530 * \\
\hline LE_96\% & $0.9418 *$ & $0.9783^{*}$ & 1.0000 & $0.9264^{*}$ & 0.1963 & 0.6248 * \\
\hline LE_50\% & $0.8528^{\star}$ & $0.9168^{*}$ & $0.9264^{*}$ & 1.0000 & 0.2308 & $0.6268^{*}$ \\
\hline FR_96\% & 0.1853 & 0.2212 & 0.1963 & 0.2308 & 1.0000 & $0.7841^{*}$ \\
\hline FR_50\% & $0.6320 *$ & $0.6530 *$ & $0.6248^{\star}$ & $0.6268^{*}$ & $0.7841^{\star}$ & 1.0000 \\
\hline
\end{tabular}

*statistical significance at $p<0.05$

correlation with the remaining extracts was found for the 50\% ethanol fruit extract (0.6248-0.7841). Particularly noteworthy is the ethanolic (96\%) fruit extract. This extract only correlated with 50\% alcohol-water extract from the same part of the plant, whereas with other samples tested it showed only a weak correlation at the values of 0.1853 to 0.2308 . This correlation was outside the assumed level of significance $p<0.05$. The above may indicate that the extract contained a different chemical composition.

The evaluation of the correlation matrix carried out for alcoholic and alcohol-water extracts from flowers, leaves and fruits showed similar conclusions - a much lower correlation of ethanol fruit extract with the remaining extracts. Figure 1 A proves these conclusions and shows the first two main components of PC1 and PC2, representing, respectively, $73.74 \%$ and $21.46 \%$, which gives a total of $95.20 \%$ of the variance of the primary variables. In addition, the first two components resemble the original variables to a very good degree, as evidenced by the length of the vectors reaching almost the edge of the circle, which supports the conclusions on the difference of fruit extracts from the remaining parts of the plant.

In the next stage of the statistical analysis, the quantity of the single components of the extracts was evaluated. In order to assess which compounds differentiated the composition of all extracts, classification tests and the principal component analysis (PCA) were performed (figure 1B). As can be seen from figure 1B, the metabolites that discriminate between the extracts from different parts of $C$. almaatensis were cyanidin 3-glucoside and quercetin 3-galactoside. Their content in the tested extracts was 0.0$0.0877 \mathrm{um} / \mathrm{g}$ and 0.0207-0.3336 um/g, respectively.

Comparative quantitative analysis of flower extracts of both studied species - Crataegus almaatensis (Ca) and $C$. oxyacantha $(\mathrm{Co})$ - revealed a very high correlation (0.8681-
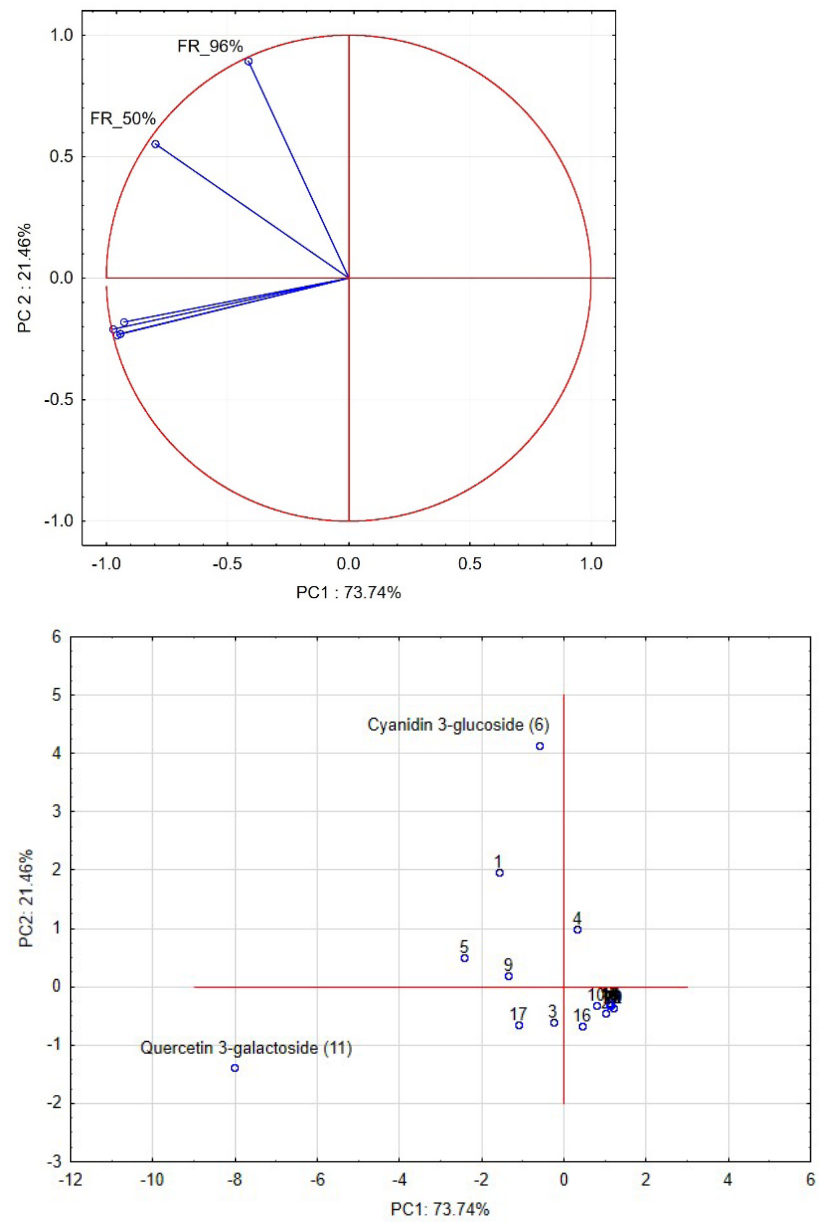

Figure 1: (A) Factor loads of PC1 vs PC2; (B) The determination of components that discriminate the differences between the extracts based on PCA analysis.

0.9201) between alcoholic and water-alcoholic extracts (Table 4). This conclusion confirms similar potential of both species. 


\subsection{Radical scavenging tests}

LC-MS analysis of Crataegus almaatensis extracts from different organs clearly showed a wide variety of phenolic compounds present in high concentrations in the studied samples. Since antioxidant potential is essential for the establishment of health benefits in food products $[34,35]$, the authors found it important to determine the antioxidant capacity of phytochemical constituents present in Crataegus almaatensis. For this purpose two assays were applied (DPPH radical test and Folin-Ciocalteu assay) to determine the actual scavenging power of Crataegus almaatensis extracts, in comparison to the commonly available $C$ oxyacantha (Table 5 ). In case of DPPH radical, $\mathrm{IC}_{50}$ values were calculated and used as a tool for comparing the antioxidant strength. For the FolinCiocalteu assay the GAE value was used for that purpose.

The comparison of different parts of Crataegus almaatensis revealed that the total phenolic content decreased from flower to leaves, and then to fruits. The amount of total phenolic compounds found in the studies show that flowers of Crataegus almaatensis were slightly more active than flowers of $C$. oxyacantha. We found that the richest part of the Crataegus almaatensis in polyphenols were extract of leaves with their concentration at $218 \pm 9 \mathrm{mg} / \mathrm{g}$, followed by $C$. almaatensis flowers extract with $180 \pm 7 \mathrm{mg} / \mathrm{g}$, which was almost 20 percent higher from $C$. oxyacantha flowers extract, which has $151 \pm 8 \mathrm{mg} / \mathrm{g}$ of total phenolic content. Fruits of Crataegus almaatensis have the lowest value of total phenolics at $88-92 \mathrm{mg} / \mathrm{g}$. Similar pattern was observed for the free radical scavenging activity. The most potent extract was the extract obtained from leaves ( $\mathrm{IC}_{50} 48 \pm 2 \mu \mathrm{g} / \mathrm{ml}$ ), then the one obtained from flowers ( $\mathrm{IC}_{50} 80 \pm 5 \mu \mathrm{g} / \mathrm{ml}$ ) with the one obtained from fruits the weakest $\left(\mathrm{IC}_{50}=230 \pm 19 \mu \mathrm{g} / \mathrm{ml}\right)$. Crataegus almaatensis flowers extract can be directly compared to a commonly available tea from $C$. oxyacantha flowers. The latter, commonly used material in Europe, exhibited a slightly lower antioxidant potential (IC50 $=100 \pm 9 \mu \mathrm{g} / \mathrm{ml}$ ) when compared to the Kazakh species, however, according to the above described results of statistical analysis, the composition of flower extracts of both species are comparable and correlated. The radical scavenging results can confirm high antioxidant activity of the tested Kazakh species of hawthorn in relation to other known species. Also, it is worth mentioning that the leaf extract was found to be more active than the flower extract, which can shed new light on the application of hawthorn leaves in the pharmacotherapy. The tests were performed also on a solution of quercetine - a flavonoid known as a radical scavenger. Its antioxidant potential (IC50 of 24) confirms
Table 4: The comparison of flower extracts from both tested hawthorn species: $C$. almaatensis and $C$. oxyacantha expressed in correlation values.

\begin{tabular}{lll}
\hline Variable & & \\
& Co_FL_50\% & Co_FL_96\% \\
\hline Ca_FL_96\% & 0.8792 & 0.8681 \\
Ca_FL_50\% & 0.9201 & 0.9037 \\
\hline
\end{tabular}

Table 5: The results of antioxidant study and total phenolic content determination on the extracts prepared from Crataegus almaatensis and Crataegus oxyacantha. (SD - standard deviation).

\begin{tabular}{lllll}
\hline Plant source & $\begin{array}{l}\text { Plant } \\
\text { organ }\end{array}$ & Solvent & $\begin{array}{l}\mathrm{DPPH}: \mathrm{IC}_{50} \\
(\mu \mathrm{g} / \mathrm{mL}) \pm \text { SD }\end{array}$ & $\begin{array}{l}\mathrm{GAE}(\mathrm{mg} / \mathrm{g}) \\
\pm \mathrm{SD}\end{array}$ \\
\hline $\begin{array}{l}\text { Crataegus } \\
\text { almaatensis }\end{array}$ & flowers & EtOH 96\% & $80 \pm 2$ & $160 \pm 4$ \\
& fruits & EtOH $96 \%$ & $215 \pm 11$ & $92 \pm 3$ \\
& & EtOH 50\% & $230 \pm 19$ & $88 \pm 3$ \\
& leaves & EtOH 96\% & $160 \pm 5$ & $110 \pm 5$ \\
& & EtOH 50\% & $48 \pm 2$ & $218 \pm 9$ \\
$\begin{array}{l}\text { Crataegus } \\
\text { oxyacantha }\end{array}$ & flowers & EtOH 96\% & $400 \pm 11$ & $64 \pm 7$ \\
Quercetin & & EtOH 50\% & $100 \pm 9$ & $151 \pm 8$ \\
& & & $24 \pm 3$ & - \\
\hline
\end{tabular}

strong antioxidant properties of hawthorns' extracts - the most active one: $50 \%$ ethanol extract from the leaves of the Kazakh species was only two times weaker from pure quercetin.

Extracts obtained with ethanol 50\% were more antioxidant in this model than the extracts obtained with ethanol $96 \%$. This might be due to a higher concentration of polar phenolic glycosides, which were better extracted with higher percentage of water.

There are similar works on other species of hawthorn, Abu-Gharbieh and Shehad have determined total phenolic content using Folin-Ciocalteu reagent and DPPH radical scavenging activity for Crataegus azarolous var. eu-azarolous Maire leaves, the results for ethanol extract were $1.5 \mathrm{mg} \mathrm{CAE} / \mathrm{g}$ and $\mathrm{IC}_{50} 129.2 \mu \mathrm{g} / \mathrm{ml}$ [36]. In comparative studies of Tunisian wild Crataegus azarolus and $C$. monogyna leaves the total phenols content were in the range of 4006.27 and $2683.85 \mathrm{mg}$ CAE/100 fresh weight for two species respectively, while antioxidant activity determined by DPPH and ferric reducing-antioxidant assay were166.50-168.18 $\mu \mathrm{mol} / \mathrm{g}$ fw and 365.32-378.07 $\mu \mathrm{mol} \mathrm{Fe2}{ }^{+} / \mathrm{g}$ fw respectively [25]. Bahri-Sahloul and co-authors have found the total phenols of Crataegus azarolous var. aronia 
(L.) Rouy \& E.G.Camus and C. azarolous var. eu-azarolus flowers to be in range 45.6-1014.2 mg GAE/100 dw, while antioxidant activity by DPPH and ABTS+ radicals showed results in the range of $\mathrm{TEAC}_{\mathrm{DPPH}} 317-893 \mu \mathrm{mol}$ Trolox/100 g DW and TEAC ABTS+ 966-1608 $\mu$ mol Trolox/100 g DW [22]. Studies determining total phenolic content of Crataegus pentagyna Waldst. \& Kit. ex Willd on leaf and flower extract showed $206 \mathrm{GAE} \mathrm{mg/g}$ and $184 \mathrm{GAEmg} / \mathrm{g}$ extract respectively and scavenged ABTS (TEAC 0.64 and $0.65 \mu \mathrm{mol}$ Trolox equivalent to1 $\mathrm{mg} / \mathrm{ml}$ extract respectively) [37].

Our study shows the importance of Crataegus almaatensis in delivering active phenolics and being able to produce high quantities of active compounds similarly to the European officinal species. This was confirmed by a marked diversity of the extracts and also significant antioxidant potential of Crataegus almaatensis. Results obtained herein point out to the need for another pharmacopoeial monograph, which could find its place in the Pharmacopoeia of the Republic of Kazakhstan.

\section{Conclusions}

Our study shows the importance of Crataegus almaatensis in delivering active phenolics, similarly to the European officinal species. A multitude of secondary metabolites - flavonoids and phenolic acids were identified and quantified in the extracts of both species, which is certainly expressed by their high antioxidant capacity. The leaves of Crataegus almaatensis were found to deliver the highest amount of natural products among the tested parts of the plant, and 50\% ethanol was selected as a better extractant in comparison with $96 \%$ ethanol. Statistical analysis performed on the quantitative data showed a significant difference of the fruit extracts, based on the content of two metabolites: cyanidin 3-glucoside and quercetin 3-galactoside. Leaf and flower extracts (the latter - of both species) were highly correlated. These findings underline a high value of $C$. almaatensis species, in relation to the European species: Crataegus oxyacantha.

Conflict of interest: The authors state no conflict of interests.

\section{References}

[1] Edwards J.E., Brown P.N., Talent N., Dickinson T.A., Shipley P.R., A review of the chemistry of the genus Crataegus, Phytochemistry, 2012, 79, 5-26.
[2] Rastogi S., Pandey M. M., Rawat A. K., Traditional herbs: a remedy for cardiovascular disorders, Phytomedicine, 2016, 23 (11), 1082-1089.

[3] Blumenthal M., The ABC Clinical Guide to Herbs, American Botanical Council Austin, Texas, 2003, 235-247

[4] Tassell M.C., Kingston R., Gilroy D., Lehane M., Furey A., Hawthorn (Crataegus spp.) in the treatment of cardiovascular disease, Pharmacogn. Rev., 2010, 4(7), 32-41.

[5] Barros L., Carvalho A.M., Ferreira I.C., Comparing the composition and bioactivity of Crataegus Monogyna flowers and fruits used in folk medicine, Phytochem. Anal., 2011, 22(2), 181-188.

[6] Wu J., Peng W., Qin R., Zhou H., Crataegus pinnatifida: chemical constituents, pharmacology, and potential applications, Molecules, 2014, 19(2),1685-712.

[7] Liperoti R., Vetrano D.L., Bernabei R., Onder G., Herbal Medications in Cardiovascular Medicine, J. Am. Coll. Cardiol., 2017, 69(9),1188-1199.

[8] Cai Y., Luo Q., Sun M., Corke H., Antioxidant activity and phenolic compounds of 112 traditional Chinese medicinal plants associated with anticancer, Life Sci., 2004, 74(17), 21572184.

[9] Dinesh K., Vikrant A., Zulfiqar B., Nisar K., Deo P., The genus Crataegus (Rosaceae): chemical and pharmacological perspectives, Rev. Bras. Farmacogn., 2012, 22, 1187-1200.

[10] Claudia A.M, Dana C., Madosa E., Ghiocel M., Lucian C., The chemical composition and pharmaceutical usage of Hawthorn (Crataegus monogyna L.) extracts, J. Biotechnol., 2016, 231, S59.

[11] Mukhamedova S.V., Biochemical research of hawthorn species fruits in Mari El republic, Vestnik of Kazan State Agrarian University, 2013, 15(16), 103-107, (in Russian).

[12] Romanova N.G., Haw and ash berry as promising sources for creation of functional food, Achievements of Science and Technology of AIC, 2008, 9, 59-62, (in Russian).

[13] Sakipova Z., Wong N.S., Bekezhanova T., Sadykova A., Shukirbekova A., Boylan F., Quantification of santonin in eight species of Artemisia from Kazakhstan by means of HPLC-UV: Method development and validation, PLoSOne, 2017, 12(3), http://journals.plos.org/plosone/article?id=10.1371/ journal.pone.0173714

[14] Kartbaeva E., Donald G., Sakipova Z., Ibragimova L., Bekbolatova E., Ternynko I., et al., Antinociceptive activity of Cistanche salsa stolons, growing in the Republic of Kazakhstan, Rev. Bras. Pharmacogn., 2017, 27, 587-591.

[15] Lee S. K., Mbwambo Z. H., Chung H., Luyengi L., Gamez E. J. C., Mehta R. G., et al., Evaluation of the antioxidant potential of natural products, Comb. Chem. High Throughput Screen., 1998, 1, 35-46.

[16] Kukula-Koch W., Koch W., Angelis A., Halabalaki M., Aligiannis N., Application of $\mathrm{pH}$-zone refining hydrostatic countercurrent chromatography (hCCC) for the recovery of antioxidant phenolics and the isolation of alkaloids from Siberian barberry herb, Food Chem., 2016, 203, 394-401.

[17] Koch W., Kukula-Koch W., Gtowniak K., Catechin composition [37] and antioxidant activity of black teas in relation to brewing time, JAOAC, 2017, 100, 6, 1-6.

[18] Kukula-Koch W., Aligiannis N., Halabalaki M., Skaltsounis A. L., Glowniak, K., Kalpoutzakis E., Influence of extraction 
procedures on phenolic content and antioxidant activity of Cretan barberry herb. Food Chem., 2013, 138, 406-413.

[19] Sticher O., Meier B., Hawthorn (Crataegus): Biological Activity and New Strategies for Quality Control, Phytomedicines of Europe, 1998 , 241-262

[20] Liu P., Composition of Hawthorn (Crataegus spp.) fruits and leaves and Emblic Leafflower (Phyllanthus emblica) fruits, PhD thesis, Forum University of Turku, Turku, 2012.

[21] Nabavi S.F., Habtemariam S., Ahmed T., Sureda A., Daglia M., Sobarzo-Sánchez E., et al., Polyphenolic Composition of Crataegus monogyna Jacq.: From Chemistry to Medical Applications, Nutrients, 2015, 7(9), 7708-7728.

[22] Bahri-Sahloul R., Ammar S., Fredj R.B., Saguem S., Grec S., Trotin F., et al., Polyphenol contents and antioxidant activities of extracts from flowers of two Crataegus azarolus L. varieties, Pak. J. Biol. Sci., 2009, 12(9), 660-668.

[23] Melikoğlu G., Bitiş L., Meriçli A.H., Flavonoids of Crataegus microphylla, Nat. Prod. Res., 2004,18(3), 211-213.

[24] Wenmin L., Guanhua C., Tong C., Determination of Flavones in Crataegus pinnatifida by Capillary Zone Electrophoresis, J. Chromatogr. Sci., 2003, 41, 87-91.

[25] Belkhir M., Rebai O., Dhaouadi K., Congiu F., Tuberoso C.I., Amri M., et al., Comparative Analysis of Tunisian Wild Crataegus azarolus (Yellow Azarole) and Crataegus monogyna (Red Azarole) Leaf, Fruit, and Traditionally Derived Syrup: Phenolic Profiles and Antioxidant and Antimicrobial Activities of the Aqueous-Acetone Extracts, J. Agric. Food Chem., 2013, 61(40), 9594-9601

[26] Gao Z., Jia Y., Cui T., Han Z., Qin A., Kang X., et al., Quantification of Ten Polyphenols in the Leaves of Chinese Hawthorn (Crataegus pinnatifida Bge. var. major N.E. Br.) by HPLC, Asian J. Chem., 2013, 25(18), 10344-10348.

[27] Chen G., Liu W., Determination of Six Functional Compounds in Crataegus pinatifida BGE by Capillary Zone Electrophoresis, J. Liq. Chromatogr. Relat. Technol ., 2005, 28(2), 223-232.

[28] Orhan I., Özçelik B., Kartal M., Özdeveci B., Duman H., HPLC Quantification of Vitexine-2"-O-rhamnoside and Hyperoside in Three Crataegus Species and Their Antimicrobial and Antiviral Activities, Chromatographia, 2007, 66, Suppl. 1, 153-157.
[29] Zhang Z., Chang Q,, Zhu M,, Huang Y,, Ho W,K,, Chen Z., Characterization of antioxidants present in hawthorn fruits, J. Nutr. Biochem., 2001, 12(3), 144-152.

[30] Wen L., Guo X., Liu R.H., You L., Abbasi A.M., Fu X., Phenolic contents and cellular antioxidant activity of Chinese hawthorn “Crataegus pinnatifida”, Food Chem., 2015, 186, 54-62.

[31] Wen L., Guo R., You L., Abbasi A.M., Li T., Fu X., et al., Major triterpenoids in Chinese hawthorn "Crataegus pinnatifida" and their effects on cell proliferation and apoptosis induction in MDA-MB-231 cancer cells, Food Chem Toxicol., 2017, 100, 149-160.

[32] Rezaei-Golmisheh A., Malekinejad H., , Asri-Rezaei S., Farshid A.A., Akbari P., Hawthorn ethanolic extracts with triterpenoids and flavonoids exert hepatoprotective effects and suppress the hypercholesterolemia-induced oxidative stress in rats, Iran J. Basic. Med. Sci., 2015, 18(7), 691-699.

[33] Mojca S., Petra K., Majda H., Andreja R.H., M. S., Željko K., Phenols, proanthocyanidins and their antioxidant activities, Food Chem, 2005, 89, 191-198.

[34] Orcic D., Franciskovic M., Bekvalac K., Svircev E., Beara I., et al., Quantitative determination of plant phenolics in Urtica dioica extracts by high-performance lilquid chromatography coupled with tandem mass spectrometric detection. Food Chem., 2014 143, 48-53.

[35] Kozyra M., Biernasiuk A., Malm A. Analysis of phenolic acids and antibacterial activity of extracts obtained from the flowering herbs of Carduus acanthoides L., Acta Pol. Pharm.,2017, 74, 161-172.

[36] Abu-Gharbieh E., Shehab N.G., Therapeutic potentials of Crataegus azarolus var. eu- azarolus Maire leaves and its isolated compounds, BMC Complement Altern. Med., 2017, 17(1), 218.

[37] Bedreag C.F., Trifan A., Bucur L.A., Arcus M., Tebrencu C., Miron A., et al., Chemical and antioxidant studies on Crataegus pentagyna leaves and flowers, Rom. Biotechnol. Lett., 2014, 19, 9859-9867. 